\title{
A Compendium of Perspectives on Diabetes: A Challenge for Sustainable Health in the Modern Era
}

\author{
Amit K Verma ${ }^{1} *$ \\ Yamini Goyal ${ }^{1, *}$ \\ Deepti Bhatt' \\ Kapil Dev' \\ Mohammed A Alsahli ${ }^{2}$ \\ Arshad Husain Rahmani ${ }^{2}$ \\ Ahmad Almatroudi ${ }^{2}$ \\ 'Department of Biotechnology, Jamia \\ Millia Islamia, New Delhi, India; \\ ${ }^{2}$ Department of Medical Laboratories, \\ College of Applied Medical Science, \\ Qassim University, Buraidah, 5257I, \\ Saudi Arabia \\ *These authors contributed equally to \\ this work
}

\begin{abstract}
Diabetes is a chronic illness. Hyperglycemia is the characteristic of this disorder. Diabetes is a global crisis which affects the economy and health of all nations. Over the last decades, the number of individuals living with diabetes has significantly increased worldwide. Asia is a key epicenter of the emerging diabetes epidemic, with China and India the two nations having the highest number of diabetic people. Economic development, modernization, unhealthy diet, population aging, and sedentary lifestyles are the major factors responsible for the increasing diabetes epidemic. Diabetes is associated with several complications, and cardiovascular disease is the most important cause of morbidity and mortality among people with diabetes. These life-threatening problems can be prevented or delayed by proper management of diabetes. Lifestyle modification is an important factor to decrease the diabetes risk. The frequency of diabetic complications will rise if there is a lack of costeffective and sustainable interventions. Hence, prevention of diabetes and its complications such as diabetic retinopathy and cardiovascular disease should be a crucial part of all future health-related public policies among all nations. This review summarizes current epidemiological aspects of diabetes in the world along with its complications, preventive measures, and treatment.
\end{abstract}

Keywords: diabetes, hyperglycaemia, modernization, cardiovascular disease, diabetic retinopathy

\section{Introduction}

Diabetes is a chronic disorder where the human body cannot secrete any insulin hormone or produces ineffective or insufficient insulin, which causes an increase in blood glucose levels. The pancreas gland secretes insulin hormone, and it transports glucose from blood to cells where glucose is broken down in the presence of oxygen. Insufficient insulin or incapability to effectively respond to insulin causes hyperglycemia or high blood sugar levels, which is the hallmark sign of diabetes. Unchecked hyperglycemia for a long time period can cause damage to several body organs which leads to critical health problems such as nephropathy, neuropathy, retinopathy and heartrelated disease. These life-threatening problems can be prevented or delayed by proper management of diabetes. ${ }^{1}$ According to the International Diabetes Federation (IDF), approximately 463 million people (ages 20-79 years) were living with diabetes worldwide in 2019 . This age group represents $9.3 \%$ of the world population. This number is projected to rise to 578 and 700 million by 2030 and 2045, respectively, and the biggest rises will occur in the areas where economies are moving from low- to middle-income status. Economic development, modernization, unhealthy diet intake, population aging and sedentary lifestyles are the major factors responsible for the increasing diabetes
Correspondence: Amit K Verma

Medical Biotechnology Lab, Department of Biotechnology, Jamia Millia Islamia, Srinivasa Ramanujan Block, Mujeeb Bagh, New Delhi, I I0025, India

Email averma2@jmi.ac.in 
epidemic. $^{2,3}$ In this review, we discuss the classification and world picture of diabetes. We then describe the prevalence, incidence and complications of diabetes. We also discuss recommendations from various studies for preventing diabetes.

\section{Diagnosis and Classification of Diabetes}

Diabetes has been mainly classified into three types: type 1 diabetes (T1D), type 2 diabetes (T2D) and gestational diabetes (GD). Monogenic diabetes and secondary diabetes are less common forms of diabetes (Figure 1). ${ }^{4}$ T1D results from the destruction of insulin-secreting pancreatic betacells which results in a complete deficiency of insulin. An interaction of genetic susceptibility and environmental agents (such as toxins, viral infections, or a few dietary elements) has been implicated in triggering this destructive process. T1D can develop at any age but is mostly seen in adolescents and children. Almost $90 \%$ of all cases of diabetes belong to T2D. T2D is mostly found in middleaged individuals and incidence in children and, young adults has increased in recent times due to increasing levels of unhealthy eating habits, obesity, and sedentary lifestyle. T2D is characterized by hyperglycemia linked to inability to adequately respond to insulin. However, the specific etiologies of the disease are unknown. Gestational diabetes usually occurs during the 2 nd or 3 rd trimester of pregnancy. However, it can affect at any time of pregnancy. First-diagnosed high blood glucose level during pregnancy is categorized as GD or hyperglycemia in pregnancy. During pregnancy, GD accounts for about $75-90 \%$ of all incidents of high sugar levels. GD arises because of insulin resistance due to production of placental hormones. An autosomal dominant mutation in a single gene causes monogenic diabetes. Neonatal diabetes and maturity onset diabetes of young (MODY) conditions are examples of monogenic diabetes. Hyperglycemia onset at an early age or before 25 years of age is characteristic of MODY. However, MODY can occur at older ages as well. When diabetes is diagnosed within the first six months of life it is called congenital or neonatal diabetes. Secondary diabetes occurs due to other disease complications including due to drugs (corticosteroids), pancreatic disease (pancreatitis) or hormonal disturbances (Cushing syndrome).$^{5-7}$ Blurred vision, frequent urination, tiredness, and excessive thirst are common T1D and T2D symptoms. Among other symptoms, persistent fungal infections in skin, numbness in feet and hands and slow healing wounds are some specific T2D symptoms. ${ }^{4}$ Symptoms of hyperglycemia in pregnancy are not clear and it is hard to differentiate them from usual pregnancy signs and symptoms. ${ }^{2}$ Diabetes can be diagnosed by observing increased glucose levels in blood. For diagnosing diabetes, 2-h plasma glucose (2-h PG) value or fasting plasma glucose (FPG) value is observed during the 75-g glucose tolerance test. Diabetes

Type 1 diabetes

Type 2 diabetes

Gestational diabetes

Monogenic diabetes

- Neonatal diabetes

- MODY

Secondary diabetes (arises as a complication of other diseases)

- Hormone disturbances e.g. Cushing syndrome

- Diseases of pancreas like pancreatitis.

- As a result of drugs like corticosteroids.

Figure I Classification of diabetes. 
can also be diagnosed by a glycated hemoglobin (HbAlc) test (Table 1). In absence of symptoms of hyperglycemia, if one lab test result comes between the range of diabetes, a repeat confirmatory lab test (FPG, 2-h PG, HbA1c in 75g OGTT) should be done on the next day. ${ }^{8}$ However, the actual time of $\mathrm{T} 2 \mathrm{D}$ onset is hard to determine. Consequently, about $1 / 3 \mathrm{rd}$ cases of type 2 diabetes may not be diagnosed as people do not show any symptoms for years. When remaining undiagnosed for many years, chronic hyperglycemic complications may arise. In some T2D patients, it is diagnosed when long-term hyperglycemic problems arise such as foot ulcers, kidney infection, kidney failure, and vision loss. ${ }^{4,7,9}$ The etiology of T2D is not completely understood but significant linkage of T2D with increasing weight and age and history in the family has been reported. Physical inactivity, high intake of sugarsweetened beverages and low-intake of high fibre food, depression, race/ethnicity, smoking, prediabetes, and complications associated with polycystic ovary syndrome (PCOS), hypertension or dyslipidemia are some key risk factors involved in T2D development. ${ }^{9}$ Excessive weight gain in pregnancy, PCOS, obesity, continuing smoking, family history of diabetes, older age are some risk factors of gestational diabetes. ${ }^{2}$

Key factors in T2D development are modern lifestyle and urbanization which include unhealthy diet intake and sedentary lifestyle. Several studies have confirmed that modification in lifestyle and healthier diet can prevent or delay T2D onset. ${ }^{10}$ Studies have also demonstrated that diabetes risk is not completely attributed to genetic factors. A study found that in Pima Indians, newborns of mothers with GD were at 3.7 times more risk in developing

\section{Table I Diagnosis of Diabetes}

2-h PG $\geq 11.1 \mathrm{mmol} / \mathrm{L}(200 \mathrm{mg} / \mathrm{dL})$ during OGTT using a 75 -g oral glucose load.

OR

FPG $\geq 7.0 \mathrm{mmol} / \mathrm{L}(126 \mathrm{mg} / \mathrm{dL})$. Fasting means no caloric intake for at least $8 \mathrm{~h}$.

OR

In a patient with classical symptoms of hyperglycemia, random plasma glucose $>200 \mathrm{mg} / \mathrm{dL}(\mathrm{I} / .1 \mathrm{mmol} / \mathrm{L})$.

OR

$\mathrm{HbAlc} \geq 48 \mathrm{mmol} / \mathrm{mol}$ (6.5\%).

Abbreviations: 2-h PG, 2-hour plasma glucose; OGTT, oral glucose tolerance test; FPG, fasting plasma glucose; HbAlc, glycated hemoglobin. diabetes and obesity compared with newborns with healthy mothers. ${ }^{11}$ Therefore, there is a need to focus on fetal diet during the prenatal period and in early life years. ${ }^{12}$

\section{Diabetes as an Epidemic}

In 1994, the IDF reported that over 100 million individuals had diabetes and projected that this number will increase in future decades across the world. ${ }^{13}$ Recent studies projected that by 2045 about 700 million adults (ages 20-79 years) which will be $10.9 \%$ of the world's adult population will have diabetes (Figure 2). ${ }^{2}$ A National Diabetic Statistic report revealed that about 30 million individuals were living with diabetes in 2015 and around $23 \%$ of these individuals were projected to be undiagnosed. $^{7}$

\section{Global Situation}

In 2019, 9.3\% of the world's adults (ages 20-79 years) had diabetes. This represents 463 million people and this number is more than the number predicted by the World Health Organization (WHO) in 2014. ${ }^{2,14}$ The IDF provided data of 10 nations worldwide with the most diabetic patients in 2019 (Figure 3) and predicted the top nations with most diabetic patients by 2030 and 2045 (Figures 4 and 5). Out of all the top countries, four countries in 2019, 2030 and five countries in 2045 are from Asia. ${ }^{2}$ Due to rapid urbanization, modernization and economic development, Asia will become the epicenter of world diabetes epidemic. ${ }^{15}$ These factors are also causing significant increase in the number of people with diabetes among Gulf countries of the Middle East. ${ }^{16}$ The highest diabetes prevalence was observed in developing countries instead of developed nations. About $80 \%$ of diabetic patients are living in middle- and low-income societies and nations. ${ }^{17}$ Most of the people having diabetes in these countries have insufficient treatment resources, which is one more vital challenge in the future. ${ }^{18}$ Increased premature mortality and morbidity rate will have key economic and social results among these societies and countries. ${ }^{19,20}$

Challenges in developing countries related to diabetes are different from challenges in developed countries. First, in developing countries health systems are more concerned towards the cure of single diseases, instead of managing several overlapping chronic diseases. Second, the increasing diabetes prevalence is more in younger individuals (ages $<60$ years) in developing countries. Diabetes at this age also has an impact 


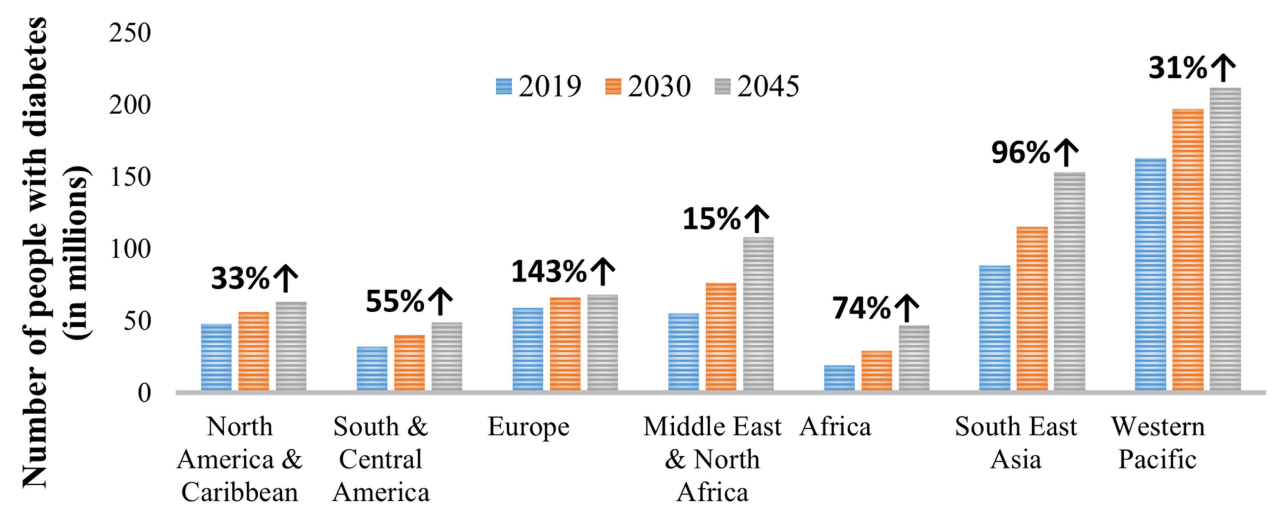

Regions

Figure 2 Number of people with diabetes globally in 2019, 2030 and 2045 (in millions).

Notes: Data from IDF Diabetes Atlas. IDF diabetes atlas, 9th edn. Brussels and Belgium; 2019. Available from: https://www.diabetesatlas.org. Accessed May II, 202I. ${ }^{2}$

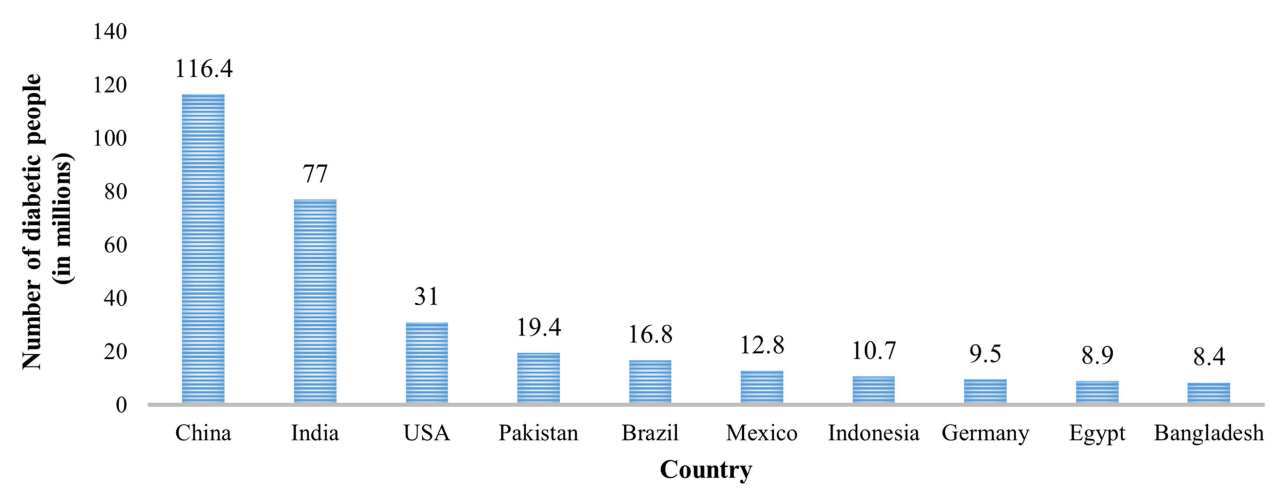

Figure 3 Number of diabetic people in 2019 (in millions).

Notes: Data from IDF Diabetes Atlas. IDF diabetes atlas, 9th edn. Brussels and Belgium; 2019. Available from: https://www.diabetesatlas.org. Accessed May II, 202I. ${ }^{2}$

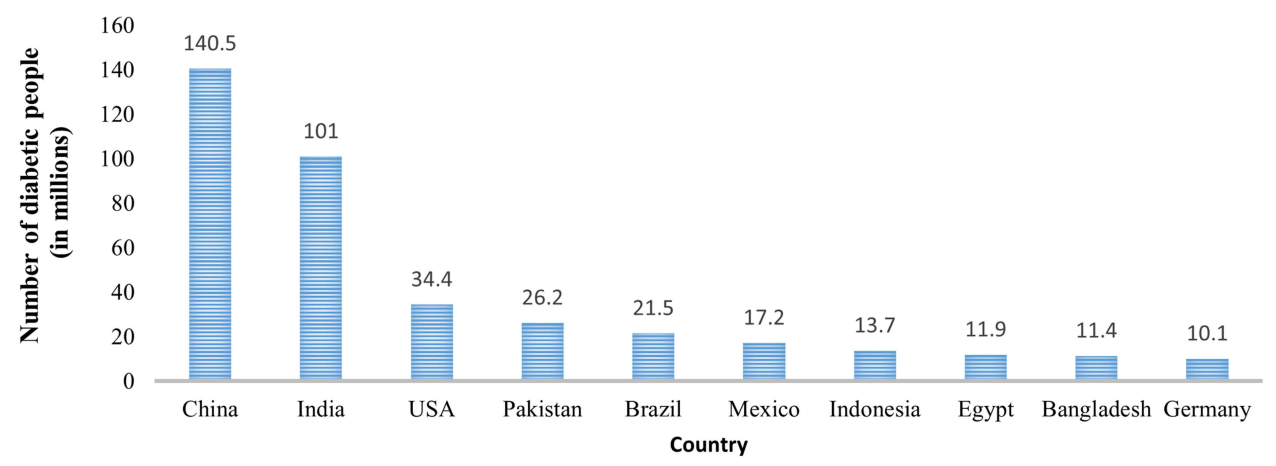

Figure 4 Number of diabetic people by 2030 (in millions).

Note: Data from IDF Diabetes Atlas. IDF diabetes atlas, 9th edn. Brussels and Belgium; 2019. Available from: https://www.diabetesatlas.org. Accessed May II, 202I. ${ }^{2}$

on peoples' work and careers. Third, the indigenous people of developing countries also have a higher number of complications such as coronary artery disease and kidney related disorders in comparison with European white populations. ${ }^{21}$ The therapeutic research focuses on novel, but costly medicines and millions of diabetes patients in developing countries cannot afford these drugs. $^{22}$ 


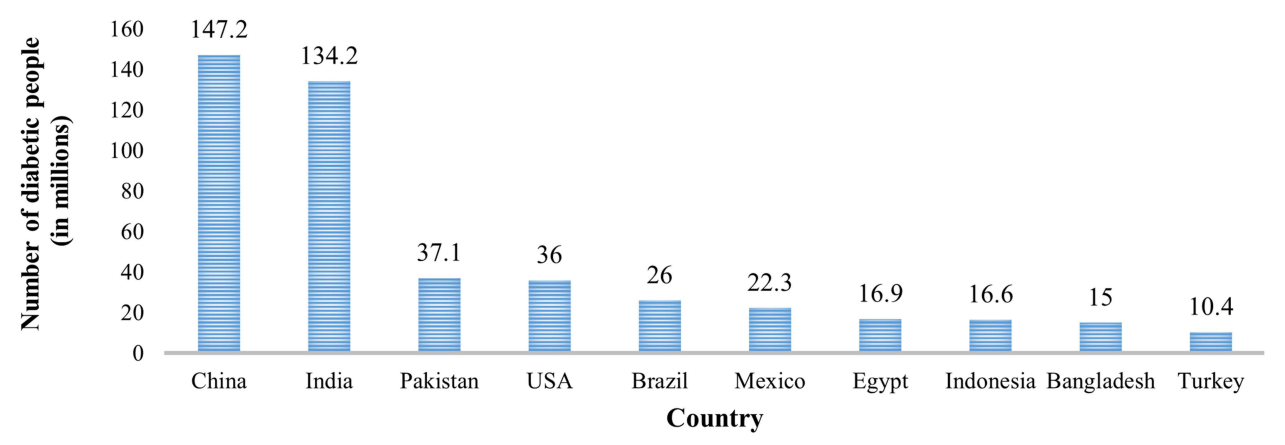

Figure 5 Number of diabetic people by 2045 (in millions).

Notes: Data from IDF Diabetes Atlas. IDF diabetes atlas, 9th edn. Brussels and Belgium; 20I9. Available from: https://www.diabetesatlas.org. Accessed May II, 202I. ${ }^{2}$

\section{Diabetes Prevalence by Types of Diabetes} According to IDF, around 1.1 million children and young adults had T1D in 2019 and the number of newly diagnosed cases (ages $0-19$ years) each year are $128,900{ }^{2}$ Hyperglycemia during pregnancy (ages 20-49 years) was found in 20.4 million of live births in 2019 which will reduce to 18.3 million by 2030 . Current data reported that there are about 373.9 million individuals (ages 20-79 years) with impaired glucose tolerance (IGT) worldwide and it is projected that this number will increase to 453.8 and 548.4 million by 2030 and 2045 , respectively. ${ }^{23,24}$

\section{Diabetes Prevalence by Age and Sex}

The diabetes prevalence considerably increases with age. ${ }^{25}$ According to studies, most diagnosed cases of diabetes are between the 4th and 7th decade of a person's life. Studies revealed that working age individuals (ages 25-69 years) have more diabetes in comparison with older individuals (ages $>69$ years). ${ }^{26}$ T1D incidence is increasing in children and teenagers (ages $<15$ years) in many regions of the world. IDF projected that every year approximately 98,200 children (ages $<15$ years) are diagnosed with T1D and it rises to 128,900 when the age group expands to $\leq 19$ years. ${ }^{2}$ Gender plays a vital role in presentation, incidence and management of the disease. ${ }^{27}$ In 2019 , the projected diabetes prevalence was slightly higher in men $(9.6 \%)$ in comparison with women $(9.0 \%)$ aged $20-79$ years. IDF estimated that approximately 17.2 million more males are diagnosed with diabetes than females. The variation in diabetes prevalence among males and females will be reduced in future as the number is expected to rise to 10.4 and $11.1 \%$ in males by 2030 and 2045 , respectively and 10 and $10.8 \%$ in females by 2030 and 2045, respectively. $^{2}$

\section{Diabetes Prevalence by Urban and Rural Regions, Income Status}

Prevalence of diabetes differs across all countries worldwide. Socioeconomic factors such as modernization, urbanization, industrialization, sedentary lifestyle and migration from rural to urban regions may influence diabetes differently among developing and developed countries. Studies reported that ethnicity plays a vital role in prevalence of diabetes in low-, middle- and high-income countries. ${ }^{28}$ Diabetes prevalence is maximum in highincome nations (10.4\%), followed by middle-income nations $(9.5 \%)$ and lowest in low-income nations (4\%). Although, the diabetes prevalence will rise to $11.9,11.8$ and $4.7 \%$ in high-, middle- and low-income nations, respectively. ${ }^{2,24}$ Urbanization is positively and strongly associated with prevalence of diabetes. ${ }^{29}$ Previous studies revealed that diabetes has been more frequently reported in urban populations in comparison with rural populations. ${ }^{28}$ The prevalence of diabetes is higher in urban regions $(10.8 \%)$ in comparison with rural regions $(7.2 \%){ }^{2}$ Out of all the diabetes patients, $67 \%$ of patients are living in urban regions. In 2019, around 310.3 million people living in urban regions had diabetes and it is predicted that this number will increase to 415.4 and 538.8 million by 2030 and 2045, respectively. ${ }^{2,24}$ Although, a meta-analysis study also found that the diabetes prevalence in rural areas of middle- and low-income nations was increased almost 5 times in 2005-2010 (8.6\%) from 1985-1989 (1.8\%). ${ }^{30}$

\section{Trends in Diabetes Incidence Increase in Diabetes Prevalence}

Over decades, the trends of diabetes demonstrate the speed and direction of evolution of the diabetes epidemic. Due to phosphate deposits mining in Nauru region, this island 
population experienced great wealth which caused changes in their lifestyle and due to modernization their diabetes prevalence increased from nearly 0 (in the 1960s) to $35 \%$ by the $1970 \mathrm{~s} .{ }^{31}$ The inactive lifestyle of the Nauru population resulted in a substantial increase in prevalence of T2D. ${ }^{32}$ The T2D prevalence in Nauru was about $50 \%$ in 1994. Though the diabetes prevalence in Nauru region was an alert for the worldwide diabetes epidemic in future, the situation in Mauritius was also a sign for the diabetes epidemic across the world. ${ }^{33}$ A 23 -year study of diabetes within different ethnic groups (mainly Asian Indians, Africans and Chinese) of Mauritius showed a growing diabetes prevalence (from $12.8 \%$ in 1987 to $23.4 \%$ in 2009) due to changes in traditional risk factors such as ethnicity, smoking, circumference of waist, hypertension, family history, body mass index, and age in its population. ${ }^{33}$ Ethnicity of India and China was similar to Mauritius ethnic groups and in 1990 Dowse and his colleagues predicted that due to globalization and modern lifestyles, diabetes prevalence would grow significantly in coming years in these regions. ${ }^{34}$ Data from India and Chinese population studies confirmed their prediction. ${ }^{4}$

The study in India covered a 6-year duration and its data represent the growing diabetes prevalence in rural and urban regions of India from 6.4 and $13.9 \%$ to 9.2 and $18.2 \%$, respectively. ${ }^{35}$ Another study also observed the growing diabetes prevalence in India over a period of time in urban as well as in rural areas. ${ }^{31}$ IDF Diabetes Atlas 9th edition reported that in 2019, 116.4 million individuals (ages 20-79 years) in China are affected with diabetes and it has more individuals with diabetes in the world in comparison with any other country. Several findings suggested that China is home to the largest number of diabetes patients (ages 20-79 years) in the world, followed by India. ${ }^{2}$ The diabetes prevalence in China increased substantially in 20 years. In 1980, the diabetes prevalence in China was $0.67 \%$, which increased to $11.6 \%$ in $2010 .^{36}$ In urban areas of China like Qingdao, diabetes prevalence had increased significantly $(11.3 \%$ to $16.5 \%)$ in 5 years (2001-2006). Furthermore, other findings suggested similar growing diabetes prevalence in Chinese rural regions. ${ }^{37}$ Brazil is another example of the growing prevalence of diabetes over 30 years. ${ }^{38}$ A comprehensive study in Brazil reported that the diabetes prevalence was $4.7 \%$ in 1996 , which increased to $10.3 \%$ in 2012 , a more than $100 \%$ increase in a 16-year time period. ${ }^{39}$ But the country with highest prevalence in 2019 was the Marshall Islands with a $30.5 \%$ diabetes prevalence rate followed by Kiribati and
Sudan with 22.5 and $22.1 \%$ rate of diabetes prevalence, respectively. ${ }^{2}$ Forouhi et al. (2019) reported that T1D incidence has been increasing with an average increase of approximately $3 \%$ per year around the world. The most noticeable rise has been observed in the $0-4$ years age group. ${ }^{40}$ Increase in diabetes prevalence has also been seen in European populations. In only one decade (1995-2005), there was a rise of $69 \%$ of prevalence of diabetes in Ontario, Canada. ${ }^{41}$ Data from the USA demonstrate an annual increase in T2D in youth (ages 10-19 years) of around $5 \%$ in $2002-2012 .{ }^{42}$ Similarly, the GD prevalence is significantly rising, primarily in high risk type 2 diabetes individuals and it may increase the diabetes prevalence worldwide. $^{43}$

\section{Decrease in Diabetes Prevalence}

Due to mining of valuable phosphate deposits, Nauruans became very rich which caused changes in their lifestyle and due to modernization in 1975, the prevalence of diabetes was very high in Nauru. ${ }^{31}$ The Nauru population had an inactive lifestyle which resulted in a substantial increase in the prevalence of T2D. ${ }^{32}$ The T2D prevalence in Nauru was about $50 \%$ in 1994. After a decade, Nauru's economy went down, and it became a poor country from being a very rich country, and its diabetes prevalence also reduced. ${ }^{3}$ Similarly, there was a reduction in prevalence of diabetes in Cuba during an economic crisis. ${ }^{44}$ These results suggested the impact of socio-economic factors in incidence and prevalence of T2D. ${ }^{3}$

\section{Diabetes: Global Healthcare Expenditure}

The economic burden of diabetes is huge, and it is expected to continue growing. In 2019, the world's healthcare expenditure on diabetes was expected to reach $\$ 760$ billion. It was $\$ 232$ billion in 2007 and projected to reach $\$ 825$ billion and $\$ 845$ billion by 2030 and 2045 , respectively (Figure 6). ${ }^{2,45}$

Diabetes-related health expenditure is not the same in different nations. In 2019, Caribbean and North America regions expended about $\$ 324.5$ billion on diabetes and this was $42.7 \%$ of global diabetes care expenditure. These regions had the maximum diabetes care expenditure per individual (ages 20-79 years) while the Southeast Asia region had the least per person diabetes expenditure among all regions. The Middle East, Africa, Southeast Asia and Central-South America regions spent considerably less and altogether contributed only $14.8 \%$ of total diabetes care expenditure (Figure 7). The USA had the 


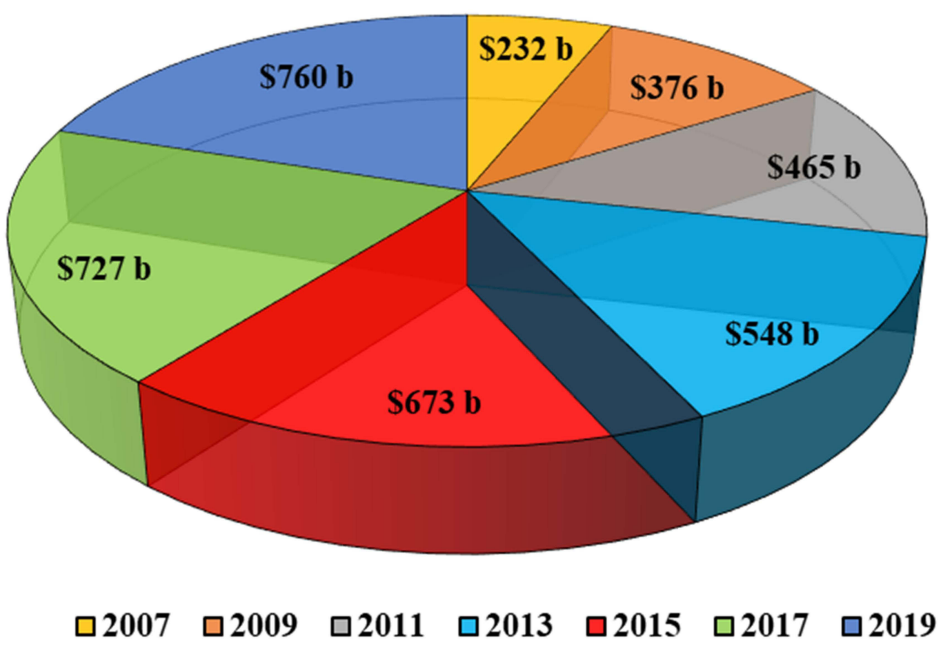

Figure 6 World healthcare expenditure (in billion/b) on diabetes (2007-2019).

Notes: Data from IDF Diabetes Atlas. IDF Diabetes Atlas, 9th Edn. Brussels and Belgium; 2019. Available from: https://www.diabetesatlas.org. Accessed May II, 202I ${ }^{2}$ and International Diabetes Federation. IDF Diabetes Atlas 8th Edition. IDF Executive Office; 2017. Available from: http://www.diabetesatlas.org/. Accessed May II, 202I. ${ }^{4}$

\section{Percentage of total diabetes-related health expenditure in 2019 by region}

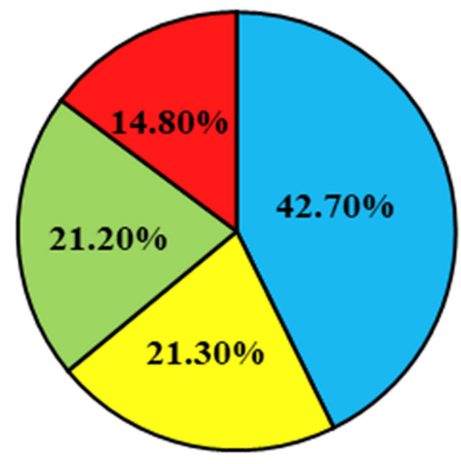

\section{口North America \& Caribbean aWestern Pacific aEurope aOthers}

Figure 7 Percentage of total diabetes-related health expenditure in 2019 by region. ${ }^{2}$

highest expenditure in 2019 ( $\$ 294.6$ billion), followed by China and Brazil with $\$ 109$ billion and $\$ 52.3$ billion, respectively on diabetes. Tuvalu, Principe and Sao Tome were among the nations with the lowest healthcare expenditure on diabetes. ${ }^{2}$

Health-care expenditure on diabetes depends on a nation's income. ${ }^{18}$ In the USA, health-care expenditure on diabetes increased almost three times from $\$ 132$ billion (2002) to $\$ 327$ billion in $2017 .{ }^{46,47}$ One of the reasons for this rise was the use of expensive and new treatments and medications for diabetes complications. Due to the growing use of costly treatments and medications for diabetes, increase in medical expenditure attributed to diabetes in future is of major concern in developing nations. ${ }^{18}$

Due to growing prevalence of diabetes, the need for expensive treatments and drugs for diabetes will increase and it will lead to an unsustainable rise in global healthcare expenditure. This will be a big challenge in the future 
for developed as well as developing countries. ${ }^{18}$ There is a crucial requirement of feasible and cost-effective interventions for prevention of diabetes and its complications to reduce future economic collapse. ${ }^{48}$

\section{Complications of Diabetes}

Diabetes is characterized by hyperglycemia. Long-term hyperglycemia may cause various complications and it is associated with long-term dysfunction, damage and failure of numerous organs, predominantly kidneys, eyes, blood vessels and nerves. Diabetic complications can be chronic (long term) or acute (short term). Chronic complications are characterized by damage to the vascular system and categorized into macrovascular complications (damage to larger blood vessels) and microvascular complications (damage to small blood vessels). ${ }^{49}$ Diabetic people have a higher risk of developing macrovascular diseases or heart disease. Heart disease is a disorder of the large arteries and an inflammatory process which leads to stroke, peripheral arterial disease and arteriosclerosis. ${ }^{50}$ Cardiovascular conditions are the leading cause of mortality and morbidity in T1D and T2D patients. ${ }^{51}$ Risk of heart disease can be decreased by lowering the increased blood pressure and blood glucose levels and by using medications that can lower cholesterol levels in diabetic patients. ${ }^{52}$ Microvascular complications lead to diabetic retinopathy, neuropathy and nephropathy and they are the key reason for mortality and morbidity in people with diabetes. ${ }^{50}$ Among all microvascular diseases, diabetic retinopathy (DR) is an extremely complicated disease, and it is one of the important and common causes of visual defect and loss of sight in adults (ages 20-74 years). ${ }^{53}$ The prevalence of DR is associated with hypertension, level of glycemic control and duration of T1D or T2D. Other risk factors such as nephropathy, chronic hyperglycemia and dyslipidemia are also associated with DR. ${ }^{54}$ Blindness and visual impairment can be prevented by timely diagnosis and treatment of the DR. ${ }^{2}$ Diabetic neuropathy may damage the autonomic and peripheral nervous systems and occurs in about $50 \%$ of all diabetic patients. Duration of diabetes and $\mathrm{HbAlc}$ level are the major risk factors of diabetic neuropathy. ${ }^{55}$ Peripheral neuropathy in diabetic patients can result from diabetic neuropathy. Peripheral neuropathy damages distal nerves of limbs and typically affects nerves in the feet. This condition encourages the development of ulcers and leads to diabetic foot complications. ${ }^{56,57}$ Diabetic nephropathy occurs in approximately $25-35 \%$ of T1D or T2D patients. ${ }^{58}$ Both chronic kidney disease and diabetes are linked with CVD and risk related to disease can be reduced by controlling blood pressure and blood glucose levels. ${ }^{2,59}$ Acute complications of diabetes such as hypoglycemia, hyperglycemic hyperosmolar state (HHS), diabetic ketoacidosis and lactic acidosis are easily preventable but still cause high morbidity and mortality in diabetic patients. ${ }^{60}$ Diabetes increases the risk of complications in the digestive, musculoskeletal and liver systems ${ }^{9,61}$ and in depression and mental health-related problems too. ${ }^{62}$ Type 2 diabetes might also enhance the risk of liver, pancreas and colorectal cancers. ${ }^{63}$ Some comorbidities such as obstructive sleep apnea, non-alcoholic fatty liver disease, and oral health diseases are also associated with diabetes. ${ }^{2,9}$ The consistent characteristic between T1D and T2D is hyperglycemia. Hence, treatment of hyperglycemia would be the prime preventive measure for complications of diabetes. ${ }^{2}$

\section{Diabetes and Musculoskeletal Disorders}

Several muscular and skeletal disorders occur in diabetes. These musculoskeletal disorders can cause function loss and pain and can also restrict the physical exercise programmes to maintain and manage the body weight of diabetes patients. ${ }^{64}$ Muscle infarction, neuropathic joints, reflex sympathetic dystrophy syndrome, Dupuytren's contracture, muscle cramps, carpal tunnel syndrome, tenosynovitis, peripheral neuropathy, adhesive capsulitis of the shoulder, diffuse idiopathic skeletal hyperostosis, stiff hands syndrome and loss of deep tendon reflexes are common musculoskeletal effects of diabetes. ${ }^{65}$ Management and assessment of musculoskeletal disorders among people with diabetes can reduce mortality, morbidity and pain. ${ }^{64}$

\section{Diabetes and Duchenne Muscular Dystrophy}

Duchenne muscular dystrophy (DMD) is an X-linked recessive condition which influences around 1 live-born male out of 3600-6000 live-born males. This disease generally begins early during childhood with delayed motor development and waddling gait. ${ }^{66}$ For development of diseases like T2D, insulin resistance and hyperinsulinemia are vital risk factors and the incidence of these factors rises (about $80 \%$ ) when patients with DMD are obese. ${ }^{67}$

\section{Diabetes and Sarcopenia}

Sarcopenia is a syndrome characterized by loss of muscle function and mass and it has been associated as a cause as 
well as a consequence of T2D. ${ }^{68}$ Sarcopenia risk is found to be increased among people with T2D. But sarcopenia in senior adults may increase the risk of development of T2D. The Hong et al. study of 89,854 Korean women and 113,913 men (mean age $=40$ years) observed that the people with lowest muscle mass related to weight of body quartiles had two-fold more risk of T2D development in comparison with the people in the highest quartile. ${ }^{69}$ Factors such as inflammation and insulin resistance can influence several muscle health components and reduced health of muscle can cause the progression and development of T2D. ${ }^{68}$

\section{Diabetic Neuropathic Cachexia}

Diabetic neuropathic cachexia (DNC) is a very rare type of diabetic neuropathy with weakly identified pathogenesis. DNC is a condition in which severe weight loss occurs quickly, generally over a period of 3-6 months. This disease is not associated with the duration or the severity of diabetes. ${ }^{70}$ Mostly cases of DNC start with quite sudden improvement in glycemic control, triggered by insulin initiation. Within a short duration of time, usually some

Table 2 IDF Recommended Nutritional Diet

\begin{tabular}{|c|c|}
\hline S. No. & Recommendations \\
\hline ।) & Eating up to three servings of fresh fruit every day. \\
\hline 2) & $\begin{array}{l}\text { Limiting alcohol intake to a maximum of two standard } \\
\text { drinks per day. }\end{array}$ \\
\hline 3) & $\begin{array}{l}\text { Eating at least three servings of vegetables every day, } \\
\text { including green leafy vegetables. }\end{array}$ \\
\hline 4) & $\begin{array}{l}\text { Choosing lean cuts of white meat, poultry or seafood } \\
\text { instead of eating processed meat. }\end{array}$ \\
\hline 5) & $\begin{array}{l}\text { Choosing nuts, a piece of fresh fruit or unsweetened } \\
\text { yoghurt for a snack. }\end{array}$ \\
\hline 6) & $\begin{array}{l}\text { Choosing unsaturated fats (olive oil, canola oil, corn oil or } \\
\text { sunflower oil) instead of saturated fats (butter, ghee, } \\
\text { animal fat, coconut oil or palm oil). }\end{array}$ \\
\hline 7) & $\begin{array}{l}\text { Choosing peanut butter instead of chocolate spread } \\
\text { or jam. }\end{array}$ \\
\hline 8) & $\begin{array}{l}\text { Choosing whole-grain bread, brown rice, or whole-grain } \\
\text { pasta instead of white bread, rice, or pasta. }\end{array}$ \\
\hline 9) & $\begin{array}{l}\text { Choosing water, coffee or tea instead of fruit juice, soda } \\
\text { or other sugar sweetened beverages. }\end{array}$ \\
\hline
\end{tabular}

days to weeks, people report serious neuropathic pain, and it is the characteristic feature of this disease. ${ }^{71}$

\section{Prevention of Diabetes}

Mostly countries (especially developed countries) have formed several schemes to tackle type 2 diabetes. Many studies report the clinical efficiency of lifestyle and pharmacologic interventions in prevention of $\mathrm{T} 2 \mathrm{D} .^{72}$ Sustainable effects have been observed in T2D prevention by change in lifestyle, while pharmacologic treatment imitates glucose-lowering therapy. ${ }^{73}$ Although clinical trials results provide a successful method for prevention of T2D, the success of this idea depends on acceptance of intervention programs among populations. ${ }^{74}$

Lifestyle intervention prevents or delays T2D onset. Therefore, International Diabetes Federation has given some suggestions for healthy eating plans (Table 2). ${ }^{4}$ Results from long-term follow-up studies in India, Finland, China and the USA showed that lifestyle intervention caused reduction in prevalence of T2D which lasts for some years even after discontinuing the intervention. ${ }^{75-80}$ Tuomilehto and his colleagues also reported that a 3.2-year intervention in physical activity and diet in a Finnish population resulted in a $58 \%$ reduction of T2D risk. ${ }^{72}$ Moreover, studies suggested that environment of early life and in utero has a significant impact on T2D risk in adulthood. So, there is a need to focus on fetal diet during prenatal period and in early life years. ${ }^{12}$ But in the case of T1D, while it is possible to manage the disease at present, there is no effective and safe intervention to prevent it. ${ }^{81}$

In 2017, about 4 million people are projected to die due to diabetes and that is equal to 1 death in every 8 seconds. ${ }^{4}$ Deaths caused by diabetes are more than the total deaths due to infectious disorders ( 0.4 million, 1.1 million and 1.8 million deaths from malaria, AIDS and tuberculosis, respectively in 2015). ${ }^{82}$ Several studies suggested that lifestyle intervention, intensive control of lipid and blood pressure and glycemic management are cost-saving methods in prevention of diabetes. ${ }^{83}$ The Indian Diabetes Prevention Program (IDPP1), which was a 3-year randomized control trial, reported that metformin and lifestyle modification helped to prevent T2D in patients with IGT. ${ }^{84}$ Another 3-year randomized control study, the Diabetes Community Lifestyle Improvement Program (D-CLIP) of 578 obese Asian Indians reported that step by step prevention of diabetes in prediabetic people can efficiently decrease incidence of diabetes. ${ }^{85}$ 


\section{Treatment of Diabetes}

Healthy lifestyle is the main determinant in diabetes treatment. Physical exercise, food intake, body weight maintenance, quit smoking plan, reduction in alcohol consumption are important factors in maintaining a healthy lifestyle. If change in lifestyle is not enough to control blood glucose levels, then oral medications are used to treat hyperglycemia. Metformin is the most highly used antidiabetic medication in the treatment of T1D and T2D globally. When single oral medication is not enough for the treatment of diabetes, several combination therapies are now present which include SGLT2 inhibitors, amylin analogues, gliptins inhibitors (for T1D and T2D) and sulfonylureas, glitazones, GLP-1R agonists, AG inhibitors, dopamine agonists (for T2D). In cases where oral drugs are not able to regulate hyperglycemia, injections of insulin may be advised. Along with blood glucose level, it is important to control blood pressure. With the management of lifestyle and medications, people with diabetes can live long and healthy lives. ${ }^{86,87}$

\section{Therapeutic Intervention of Phytochemicals in Diabetes}

In the last few years, use of traditional or conventional medicines has received considerable recognition around the globe. Several varieties of conventional medicines have been used such as Unani medicines, conventional Chinese medicines and Ayurvedic medicines. ${ }^{88}$ Long-term usage of insulin and oral hypoglycemic drugs in diabetes patients can result in several side-effects such as gastrointestinal diseases (nausea, diarrhea and vomiting), hypoglycemic episodes, hepatorenal and edema syndromes. ${ }^{89,90}$ These side-effects lead to increased usage of traditional medicines in diabetes patients. ${ }^{91,92}$ Medicinal plants contain numerous phytochemicals, and some compounds are medically and therapeutically efficient. Mostly plants have amino acids, sterols, carotenoids, tannins, mucilages, coumarins, flavonoids, saponins, and essential oils. Therapeutic actions of medicinal plants depend on the different phytochemicals classes interactions. ${ }^{93}$ Several studies have reported the antidiabetic activities of numerous isolated plant compounds. ${ }^{94}$ Plants such as soybean, bitter melon, garlic, cocoa, walnut, aloe, caper, nettle, fenugreek, melon, coffee, sage, yerba mate, black and green tea have medicinal properties and are commonly utilized in diabetes and its associated comorbidities treatment. Compounds of these medicinal plants are used as antidiabetic agents with main consideration to compounds like berberine, trigonelline, gurmarin, fukugetin, phlorizin, amorfrutins, palmatine, gymnemic acids and honokiol. ${ }^{95}$ Anti-hyperglycemic effects can resultfrom plant treatments which are commonly recognized by their ability to enhance the function of pancreatic tissue resulting from reduced absorption of glucose in the intestine or increased secretion of insulin. ${ }^{96}$

\section{Conclusion}

In the last 2-3 decades, diabetes has reached epidemic levels worldwide. Diabetes is a global crisis which affects the economy and health of all nations. This epidemic is predominantly driven by urbanization, rapid industrialization and sedentary lifestyles. Rapid economic growth and changes in lifestyle are the major reasons for the increased prevalence of diabetes. Several studies have determined the effect of intrauterine environment to understand the future risk of T2D. Diabetes increases the risk of several life-threatening and serious problems and if not effectively controlled or managed, it can lead to premature death. Lifestyle modification is an important factor to decrease the risk of diabetes and its associated complications. The frequency of diabetic complications will rise with a lack of cost-effective and sustainable interventions. Hence, prevention of diabetes and its complications such as diabetic retinopathy and cardiovascular disease should be a crucial part of all future health-related public policies among all nations.

\section{Ethics Approval and Consent to Participate}

The current review does not require ethical approval.

\section{Author Contributions}

All authors made substantial contributions to conception and design, acquisition of data, or analysis and interpretation of data; took part in drafting the article or revising it critically for important intellectual content; agreed to submit to the current journal; gave final approval of the version to be published; and agree to be accountable for all aspects of the work.

\section{Funding}

The current review did not receive funds from any outside source. 


\section{Disclosure}

The authors of the current review declared they do not have any conflicts of interest for this work.

\section{References}

1. DeFronzo RA, Ferrannini E, Zimmet P, Alberti G. International Textbook of Diabetes Mellitus. John Wiley \& Sons; 2015.

2. IDF Diabetes Atlas. IDF diabetes atlas, 9th edn. Brussels and Belgium; 2019. Available from: https://www.diabetesatlas.org. Accessed May 11, 2021.

3. Zimmet PZ. Diabetes and its drivers: the largest epidemic in human history? Clin Diabetes Endocrinol. 2017;3(1):1. doi:10.1186/s40842016-0039-3

4. International Diabetes Federation. IDF diabetes atlas 8th edition. IDF Executive Office; 2017. Available from: http://www.diabetesatlas. org/. Accessed May 11, 2021.

5. Goyal R, Jialal I. Diabetes mellitus type 2. In: StatPearls. Treasure Island (FL): StatPearls Publishing; 2020.

6. American Diabetes Association. 2. Classification and diagnosis of diabetes: standards of medical care in diabetes-2020. Diabetes Care. 2020;43(Supplement 1):S14-S31. doi:10.2337/dc20-S002.

7. Mekala KC, Bertoni AG. Chapter 4 - epidemiology of diabetes mellitus. In: Orlando G, Piemonti L, Ricordi C, Stratta RJ, Gruessner RWG, editors. Transplantation, Bioengineering, and Regeneration of the Endocrine Pancreas. Academic Press; 2020:49-58.

8. Punthakee Z, Goldenberg R, Katz P. Definition, classification and diagnosis of diabetes, prediabetes and metabolic syndrome. Can J Diabetes. 2018;42:S10-S15. doi:10.1016/j.jcjd.2017.10.003

9. Zheng Y, Ley SH, Hu FB. Global aetiology and epidemiology of type 2 diabetes mellitus and its complications. Nat Rev Endocrinol. 2018;14(2):2. doi:10.1038/nrendo.2017.151

10. American Diabetes Association. 3. Prevention or delay of type 2 diabetes: standards of medical care in diabetes-2020. Diabetes Care. 2020;43(Supplement 1):S32-S36. doi:10.2337/dc20-S003.

11. Vaiserman AM. Early-Life nutritional programming of type 2 diabetes: experimental and quasi-experimental evidence. Nutrients. 2017;9(3):236. doi:10.3390/nu9030236

12. Bhutta ZA. Early nutrition and adult outcomes: pieces of the puzzle. Lancet. 2013;382(9891):486-487. doi:10.1016/S0140-6736(13) 60716-3

13. International Diabetes Federation. Diabetes Atlas. Brussels: International Diabetes Federation; 2003.

14. Lovic D, Piperidou A, Zografou I, Grassos H, Pittaras A, Manolis A. The growing epidemic of diabetes mellitus. 2020. Available from: https://www.ingentaconnect.com/content/ben/cvp/2020/00000018/ 00000002/art00003. Accessed March 15, 2020

15. Yang W, Lu J, Weng J, et al. Prevalence of diabetes among men and women in China. $N$ Engl J Med. 2010;362(12):1090-1101. doi:10.1056/NEJMoa0908292

16. Abuyassin B, Laher I. Diabetes epidemic sweeping the Arab world. World J Diabetes. 2016;7(8):165-174. doi:10.4239/wjd.v7. i8.165

17. International Diabetes Federation. IDF Diabetes Atlas. Brussels: International Diabetes Federation, Executive Office; 2011.

18. Zimmet PZ, Magliano DJ, Herman WH, Shaw JE. Diabetes: a 21st century challenge. Lancet Diabetes Endocrinol. 2014;2(1):56-64. doi:10.1016/S2213-8587(13)70112-8

19. Tillin T, Hughes AD, Godsland IF, et al. Insulin resistance and truncal obesity as important determinants of the greater incidence of diabetes in Indian Asians and African Caribbeans compared with Europeans: the Southall and Brent REvisited (SABRE) cohort. Diabetes Care. 2013;36(2):383-393. doi:10.2337/dc12-0544
20. Wändell PE, Johansson SE, Gåfvels C, Hellénius ML, de Faire U, Sundquist J. Estimation of diabetes prevalence among immigrants from the Middle East in Sweden by using three different data sources. Diabetes Metab. 2008;34(4):328-333. doi:10.1016/j.diabet.2008.01.012

21. Grant P. Management of diabetes in resource-poor settings. Clin Med. 2013;13(1):27-31. doi:10.7861/clinmedicine.13-1-27

22. van der Gronde T, Uyl-de Groot CA, Pieters T. Addressing the challenge of high-priced prescription drugs in the era of precision medicine: a systematic review of drug life cycles, therapeutic drug markets and regulatory frameworks. PLoS One. 2017;12(8). doi:10.1371/journal.pone.0182613

23. Campbell MD, Sathish T, Zimmet PZ, et al. Benefit of lifestyle-based T2DM prevention is influenced by prediabetes phenotype. Nat Rev Endocrinol. 2020;16:395-400. doi:10.1038/s41574-019-0316-1.

24. Saeedi P, Petersohn I, Salpea P, et al. Global and regional diabetes prevalence estimates for 2019 and projections for 2030 and 2045: results from the international diabetes federation diabetes atlas, 9th edition. Diabetes Res Clin Pract. 2019;157:107843. doi:10.1016/j. diabres.2019.107843

25. Zhou B, Lu Y, Hajifathalian K, et al. Worldwide trends in diabetes since 1980: a pooled analysis of 751 population-based studies with 4.4 million participants. Lancet. 2016;387(10027):1513-1530. doi:10.1016/S0140-6736(16)00618-8

26. Ogurtsova K, da Rocha Fernandes JD, Huang Y, et al. IDF diabetes atlas: global estimates for the prevalence of diabetes for 2015 and 2040. Diabetes Res Clin Pract. 2017;128:40-50. doi:10.1016/j. diabres.2017.03.024

27 Kautzky-Willer A, von Euler M, Oertelt-Prigione S. Editorial: sex and gender aspects in diabetes. Front Endocrinol. 2019;10. doi:10.3389/fendo.2019.00813.

28. Dagenais GR, Gerstein HC, Zhang X, et al. Variations in diabetes prevalence in low-, middle-, and high-income countries: results from the prospective urban and rural epidemiological study. Diabetes Care. 2016;39(5):780-787. doi:10.2337/dc15-2338

29. Goryakin Y, Rocco L, Suhrcke M. The contribution of urbanization to non-communicable diseases: evidence from 173 countries from 1980 to 2008. Econ Hum Biol. 2017;26:151-163. doi:10.1016/j. ehb.2017.03.004

30. Hwang CK, Han PV, Zabetian A, Ali MK, Venkat Narayan KM. Rural diabetes prevalence quintuples over twenty-five years in lowand middle-income countries: a systematic review and meta-analysis. Diabetes Res Clin Pract. 2012;96(3):271-285. doi:10.1016/j. diabres.2011.12.001

31. Unnikrishnan R, Pradeepa R, Joshi SR, Mohan V. Type 2 diabetes: demystifying the global epidemic. Diabetes. 2017;66(6):1432-1442. doi: $10.2337 / \mathrm{db} 16-0766$

32. Zimmet P, Taft P, Guinea A, Guthrie W, Thoma K. The high prevalence of diabetes mellitus on a Central Pacific island. Diabetologia. 1977;13(2):111-115. doi:10.1007/BF00745137

33. Magliano DJ, Soderberg S, Zimmet PZ, et al. Explaining the increase of diabetes prevalence and plasma glucose in mauritius. Diabetes Care. 2012;35(1):87-91. doi:10.2337/dc11-0886

34. Dowse GK, Gareeboo H, Zimmet PZ, et al. High prevalence of NIDDM and impaired glucose tolerance in Indian, Creole, and Chinese Mauritians. Diabetes. 1990;39(3):390-396. doi:10.2337/diab.39.3.390

35. Ramachandran A, Mary S, Yamuna A, Murugesan N, Snehalatha C. High prevalence of diabetes and cardiovascular risk factors associated with urbanization in India. Diabetes Care. 2008;31 (5):893-898. doi:10.2337/dc07-1207

36. Wang L, Gao P, Zhang M, et al. Prevalence and ethnic pattern of diabetes and prediabetes in China in 2013. JAMA. 2017;317 (24):2515-2523. doi:10.1001/jama.2017.7596

37. Ning F, Pang ZC, Dong YH, et al. Risk factors associated with the dramatic increase in the prevalence of diabetes in the adult Chinese population in Qingdao, China. Diabetic Med. 2009;26(9):855-863. doi:10.1111/j.1464-5491.2009.02791.x 
38. de Almeida-pititto B, Dias ML, de Moraes ACF, Ferreira SR, Franco DR, Eliaschewitz FG. Type 2 diabetes in Brazil: epidemiology and management. Diabetes Metab Syndr Obes. 2015;8:17-28. doi:10.2147/DMSO.S72542

39. Bertoldi AD, Kanavos P, França GVA, et al. Epidemiology, management, complications and costs associated with type 2 diabetes in Brazil: a comprehensive literature review. Global Health. 2013;9 (1):62. doi:10.1186/1744-8603-9-62

40. Forouhi NG, Wareham NJ. Epidemiology of diabetes. Medicine. 2019;47(1):22-27. doi:10.1016/j.mpmed.2018.10.004

41. Lipscombe LL, Hux JE. Trends in diabetes prevalence, incidence, and mortality in Ontario, Canada 1995-2005: a population-based study. Lancet. 2007;369(9563):750-756. doi:10.1016/S01406736(07)60361-4

42. Mayer-Davis EJ, Lawrence JM, Dabelea D, et al. Incidence trends of type 1 and type 2 diabetes among youths, 2002-2012. N Engl J Med. 2017;376(15):1419-1429. doi:10.1056/NEJMoa1610187

43. Reece EA, Leguizamón G, Wiznitzer A. Gestational diabetes: the need for a common ground. Lancet. 2009;373(9677):1789-1797. doi:10.1016/S0140-6736(09)60515-8

44. Franco M, Bilal U, Ordunez P, et al. Population-wide weight loss and regain in relation to diabetes burden and cardiovascular mortality in Cuba 1980-2010: repeated cross sectional surveys and ecological comparison of secular trends. BMJ. 2013;346:f1515. doi:10.1136/ bmj.f1515

45. Bommer C, Heesemann E, Sagalova V, et al. The global economic burden of diabetes in adults aged 20-79 years: a cost-of-illness study. Lancet Diabetes Endocrinol. 2017;5(6):423-430. doi:10.1016/S22138587(17)30097-9

46. American Diabetes Association. Hogan P, Dall T, Nikolov P. Economic costs of diabetes in the US in 2002. Diabetes Care. 2003;26(3):917-932. doi:10.2337/diacare.26.3.917

47. A. D. Association. Economic costs of diabetes in the U.S. in 2017. Diabetes Care. 2018;dci180007. doi:10.2337/dci18-0007

48. Herman WH. The economic costs of diabetes: is it time for a new treatment paradigm? Diabetes Care. 2013;36(4):775-776. doi: $10.2337 / \mathrm{dc} 13-0270$

49. Chawla A, Chawla R, Jaggi S. Microvasular and macrovascular complications in diabetes mellitus: distinct or continuum? Indian $J$ Endocrinol Metab. 2016;20(4):546-551. doi:10.4103/22308210.183480

50. Petrie JR, Guzik TJ, Touyz RM. Diabetes, hypertension, and cardiovascular disease: clinical insights and vascular mechanisms. Can $J$ Cardiol. 2018;34(5):575-584. doi:10.1016/j.cjca.2017.12.005

51. Skinner MK. Epigenetic transgenerational inheritance. Nat Rev Endocrinol. 2016;12(2):68-70. doi:10.1038/nrendo.2015.206

52. Beckman JA, Paneni F, Cosentino F, Creager MA. Diabetes and vascular disease: pathophysiology, clinical consequences, and medical therapy: part II. Eur Heart J. 2013;34(31):2444-2452. doi:10.1093/eurheartj/eht142

53. Jonas JB, Sabanayagam C. Epidemiology and risk factors for diabetic retinopathy. Diabetic Retinopathy Cardiovasc Dis. 2019;27:20-37. doi:10.1159/000486262

54. Solomon SD, Chew E, Duh EJ, et al. Diabetic retinopathy: a position statement by the American Diabetes Association. Diabetes Care. 2017;40(3):412-418. doi:10.2337/dc16-2641

55. Feldman EL, Callaghan BC, Pop-Busui R, et al. Diabetic neuropathy. Nat Rev Dis Primers. 2019;5(1):1-8. doi:10.1038/ s41572-019-0092-1

56. Watterworth B, Wright TB. Diabetic peripheral neuropathy. In: AbdElsayed A, editor. Pain: A Review Guide. Cham: Springer International Publishing; 2019:911-913.

57. Davies M, Brophy S, Williams R, Taylor A. The prevalence, severity, and impact of painful diabetic peripheral neuropathy in type 2 diabetes. Diabetes Care. 2006;29(7):1518-1522. doi:10.2337/dc05-2228
58. Khoury CC, Chen S, Ziyadeh FN. Chapter 19 - pathophysiology of diabetic nephropathy. In: Kimmel PL, Rosenberg ME, editors. Chronic Renal Disease. 2nd ed. Academic Press; 2020:279-296.

59. Steinke JM. The natural progression of kidney injury in young type 1 diabetic patients. Curr Diab Rep. 2009;9(6):473-479. doi:10.1007/ s11892-009-0077-7

60. Harding JL, Pavkov ME, Magliano DJ, Shaw JE, Gregg EW. Global trends in diabetes complications: a review of current evidence. Diabetologia. 2019;62(1):3-16. doi:10.1007/s00125-018-4711-2

61. Krishnan B, Babu S, Walker J, Walker AB, Pappachan JM. Gastrointestinal complications of diabetes mellitus. World J Diabetes. 2013;4(3):51-63. doi:10.4239/wjd.v4.i3.51

62. Lin EHB, Rutter CM, Katon W, et al. Depression and advanced complications of diabetes: a prospective cohort study. Diabetes Care. 2010;33(2):264-269. doi:10.2337/dc09-1068

63. Tsilidis KK, Kasimis JC, Lopez DS, Ntzani EE, Ioannidis JPA. Type 2 diabetes and cancer: umbrella review of meta-analyses of observational studies. BMJ. 2015;350. doi:10.1136/bmj.g7607.

64. Sözen T, Başaran NÇ, Tınazlı M, Özışık L. Musculoskeletal problems in diabetes mellitus. Eur J Rheumatol. 2018;5(4):258-265. doi:10.5152/eurjrheum.2018.18044

65. Wyatt LH, Ferrance RJ. The musculoskeletal effects of diabetes mellitus. J Can Chiropr Assoc. 2006;50(1):43-50.

66. Bushby K, Finkel R, Birnkrant DJ, et al. Diagnosis and management of Duchenne muscular dystrophy, part 1: diagnosis, and pharmacological and psychosocial management. Lancet Neurol. 2010;9 (1):77-93. doi:10.1016/S1474-4422(09)70271-6

67. García JJM, Pérez GGR, Sicairos NML. Prevalencia de resistencia a la insulina y síndrome metabólico en niños obesos que acuden a la Clínica de Obesidad del Hospital Pediátrico de Sinaloa. Pediatr Mex. 2010;12(1):18-22.

68. Mesinovic J, Zengin A, De Courten B, Ebeling PR, Scott D. Sarcopenia and type 2 diabetes mellitus: a bidirectional relationship. Diabetes Metab Syndr Obes. 2019;12:1057-1072. doi:10.2147/ DMSO.S186600

69. Hong S, Chang Y, Jung HS, Yun KE, Shin H, Ryu S. Relative muscle mass and the risk of incident type 2 diabetes: a cohort study. PLoS One. 2017;12(11):e0188650. doi:10.1371/journal.pone. 0188650

70. Yusof NA, Idris NS, Zin FM. Diabetic neuropathic cachexia in a young woman. Korean J Fam Med. 2019;40(3):194-198. doi: $10.4082 / \mathrm{kjfm} .17 .0127$

71. Gibbons CH. Treatment-induced neuropathy of diabetes. Curr Diab Rep. 2017;17(12):127. doi:10.1007/s11892-017-0960-6

72. Tuomilehto J, Schwarz P, Lindström J. Long-term benefits from lifestyle interventions for type 2 diabetes prevention: time to expand the efforts. Diabetes Care. 2011;34(Supplement 2):S210-S214. doi: $10.2337 / \mathrm{dc} 11-\mathrm{s} 222$

73. Gillies CL, Abrams KR, Lambert PC, et al. Pharmacological and lifestyle interventions to prevent or delay type 2 diabetes in people with impaired glucose tolerance: systematic review and meta-analysis. BMJ. 2007;334(7588):299. doi:10.1136/ bmj.39063.689375.55

74. Schwarz PEH, Riemenschneider H. Slowing down the progression of type 2 diabetes: we need fair, innovative, and disruptive action on environmental and policy levels! Diabetes Care. 2016;39 (Supplement 2):S121-S126. doi:10.2337/dcS15-3001

75. Cederholm J, Gudbjörnsdottir S, Eliasson B, et al. Blood pressure and risk of cardiovascular diseases in type 2 diabetes: further findings from the Swedish National Diabetes Register (NDR-BP II). J Hypertens. 2012;30(10):2020. doi:10.1097/HJH.0b013e3283577bdf

76. Eeg-Olofsson K, Cederholm J, Nilsson PM, et al. Glycemic control and cardiovascular disease in 7,454 patients with type 1 diabetes: an observational study from the Swedish National Diabetes Register (NDR). Diabetes Care. 2010;33(7):1640-1646. doi:10.2337/dc100398 
77. Davis WA, Davis TME. Cardiovascular risk prediction in adults with type 1 diabetes: the Fremantle Diabetes Study. Diabetes Res Clin Pract. 2010;90(3):e75-e78. doi:10.1016/j.diabres.2010.09.015

78. Kautzky-Willer A, Stich K, Hintersteiner J, et al. Sex-specificdifferences in cardiometabolic risk in type 1 diabetes: a cross-sectional study. Cardiovasc Diabetol. 2013;12(1):78. doi:10.1186/1475-2840-12-78

79. Koivisto VA, Stevens IK, Mattock M, et al. Cardiovascular disease and its risk factors in IDDM in Europe. Diabetes Care. 1996;19 (7):689-697. doi:10.2337/diacare.19.7.689

80. Stettler C, Bearth A, Allemann S, et al. QTc interval and resting heart rate as long-term predictors of mortality in type 1 and type 2 diabetes mellitus: a 23-year follow-up. Diabetologia. 2007;50(1):186-194. doi:10.1007/s00125-006-0483-1

81. Atkinson MA, Eisenbarth GS, Michels AW. Type 1 diabetes. Lancet. 2014;383(9911):69-82. doi:10.1016/S0140-6736(13)60591-7

82. Ullah F, Afridi AK, Rahim F, et al. Knowledge of diabetic complications in patients with diabetes mellitus. J Ayub Med Coll Abbottabad. 2015;27(2):360-363.

83. Saha S, Gerdtham U-G, Johansson P. Economic evaluation of lifestyle interventions for preventing diabetes and cardiovascular diseases. Int J Environ Res Public Health. 2010;7(8):3150-3195. doi:10.3390/ijerph7083150

84. Ramachandran A, Snehalatha C, Yamuna A, Mary S, Ping Z. Costeffectiveness of the interventions in the primary prevention of diabetes among Asian Indians: within-trial results of the Indian diabetes prevention programme (IDPP). Diabetes Care. 2007;30 (10):2548-2552. doi:10.2337/dc07-0150

85. Weber MB, Ranjani H, Staimez LR, et al. The stepwise approach to diabetes prevention: results from the D-CLIP randomized controlled trial. Diabetes Care. 2016;39(10):1760-1767. doi:10.2337/dc16-1241

86. Marín-Peñalver JJ, Martín-Timón I, Sevillano-Collantes C, Del Cañizo-Gómez FJ. Update on the treatment of type 2 diabetes mellitus. World J Diabetes. 2016;7(17):354-395. doi:10.4239/wjd. v7.i17.354

87. Álvarez-almazán S, Filisola-Villaseñor JG, Alemán-GonzálezDuhart D, Tamay-Cach F, Mendieta-Wejebe JE. Current molecular aspects in the development and treatment of diabetes. $J$ Physiol Biochem. 2020;76(1):13-35. doi:10.1007/s13105-019-00717-0
88. Teoh SL, Das S. Phytochemicals and their effective role in the treatment of diabetes mellitus: a short review. Phytochem Rev. 2018;17(5):1111-1128. doi:10.1007/s11101-018-9575-z

89. Mahomoodally MF, Mootoosamy A, Wambugu S. Traditional therapies used to manage diabetes and related complications in Mauritius: a comparative ethnoreligious study. Evid Based Complement Alternat Med. 2016;2016:1-25. doi:10.1155/2016/4523828

90. Maruthur NM, Tseng E, Hutfless S, et al. Diabetes medications as monotherapy or metformin-based combination therapy for type 2 diabetes. Ann Intern Med. 2016;164(11):740-751. doi:10.7326/ M15-2650

91. Ezuruike UF, Prieto JM. The use of plants in the traditional management of diabetes in Nigeria: pharmacological and toxicological considerations. $J$ Ethnopharmacol. 2014;155(2):857-924. doi:10.1016/j.jep.2014.05.055

92. Lee AL, Chen BC, Mou CH, Sun MF, Yen HR. Association of traditional Chinese medicine therapy and the risk of vascular complications in patients with type II diabetes mellitus. Medicine. 2016;95(3). doi:10.1097/MD.0000000000002536

93. Katiyar D, Singh V, Gilani SJ, Goel R, Grover P, Vats A. Hypoglycemic herbs and their polyherbal formulations: a comprehensive review. Med Chem Res. 2015;24(1):1-21. doi:10.1007/s00044-014-1080-3

94. Salehi B, Ata A, V Anil Kumar N, et al. Antidiabetic potential of medicinal plants and their active components. Biomolecules. 2019;9 (10):551. doi:10.3390/biom9100551

95. Ríos JL, Francini F, Schinella GR. Natural products for the treatment of type 2 diabetes mellitus. Planta Med. 2015;81(12-13):975-994. doi:10.1055/s-0035-1546131

96. Arumugam G, Manjula P, Paari N. A review: anti diabetic medicinal plants used for diabetes mellitus. J Acute Dis. 2013;2(3):196-200. doi:10.1016/S2221-6189(13)60126-2

\section{Publish your work in this journal}

Diabetes, Metabolic Syndrome and Obesity: Targets and Therapy is an international, peer-reviewed open-access journal committed to the rapid publication of the latest laboratory and clinical findings in the fields of diabetes, metabolic syndrome and obesity research. Original research, review, case reports, hypothesis formation, expert opinion and commentaries are all considered for publication. The manuscript management system is completely online and includes a very quick and fair peer-review system, which is all easy to use. Visit http://www.dovepress.com/testimonials.php to read real quotes from published authors. 